\title{
El Guadalquivir y su imagen en el siglo XIX: la construcción de un paisaje (1830-1862)
}

Francisco Javier Rodriguez Barberán, Dpto. Historia, Teoría y Composición Arquitectónicas, Universidad de Sevilla
Escribe Antoine de Latour en 1846, cuando inicia su periplo por Andalucía como parte del séquito del duque de Montpensier: "Donde no había cultivos, las flores se habían apoderado de la tierra para dibujar admirables tapices. ... Así era la ruta encantada por la que bajábamos a las orillas del Guadalquivir. El río que da vida a Andalucía se nos mostró, por fin, poco antes de llegar a Andújar. Sus aguas, un tanto turbias, tenían el tinte rosado de las del Nilo: una armonía más en el paisaje." (LATOUR, 2008: 21). Contra lo que parece ser una costumbre extendida en los libros de viajes por la España del XIX, Latour no recurre a ninguna artimaña: él conoce Egipto, país que había recorrido apenas un año antes, y la comparación, aunque subjetiva por su carácter evocador, responde en principio a la propia experiencia.

Si he elegido el texto del autor francés para arrancar este itinerario cultural en torno a la imagen del Guadalquivir es porque alberga muchos elementos de interés, que empiezan por la propia equidistancia entre la dimensión literaria y el registro de la realidad que los Études sur l'Espagne, Séville et l'Andalousie -título de la obra donde se incluye, publicada en 1855- transmiten de modo habitual. Este término medio es el que también permite explicar el sentido de la acotación cronológica que aparece al frente de este artículo: Latour se inserta dentro de un periodo crucial para la visión de Andalucia en la cultura occidental, y que se ha vinculado en numerosas ocasiones al adjetivo "romántico" (AA.W, 1985). Sin embargo, son cada vez mayores los matices que conviene establecer acerca de este vínculo entre el movimiento estético y de mentalidades que supone el Romanticismo y el colectivo de los viajeros que durante varias décadas del siglo XIX recorren Andalucía para asomarse a la misma, en muchas ocasiones, como a un "Oriente cercano y confortable" (RODRÍGUEZ BARBERÁN et ál., 2007: 113). Las fechas elegidas hacen alusión a dos hechos concretos, que tienen además el río como referencia común: en noviembre de 1830 llegaba a Sevilla a bordo de un vapor, y tras hacer escala en Gibraltar y Cádiz, Richard Ford; en 1862 eran el barón Charles Davillier y el ilustrador Gustave Doré quienes, tras recorrer las provincias de Granada, Málaga y Cádiz, tomaron el barco en Bonanza para remontar el Guadalquivir. Ford era en aquel mo- mento un heredero de la mentalidad ilustrada que se adentra en un territorio que le fascina y le enerva a partes iguales (RODRíGUEZ BARBERÁN et ál., 2007: 111). Por su parte, Davillier y Doré estaban consolidando, a través de la palabra y la imagen respectivamente, un universo en el que la cultura quedaba oscurecida por los tópicos, condenando toda visión a una permanente búsqueda de la charanga y la pandereta. En ambos casos, el resultado del periplo andaluz serán dos libros de extraordinaria repercusión, y es que tanto el Handbook for Travellers in Spain de Ford, publicado en Inglaterra en 1844 (FORD, 2008), como el Voyage en Espagne de Davillier y Doré, editado ya por entregas en el mismo año de 1862 (DAVILLIER, 1988), alcanzaron un gran éxito en Europa. Sus visiones, sin estar enfrentadas, presentan notables diferencias, y creo que pueden ser invocadas como extremos de una imagen de España, pero sobre todo de Andalucía, sobre la que ahora vamos a reflexionar. Para ello se hace necesario volver al texto de Latour.

Cuando el viajero francés relata su primera visión del Guadalquivir cede por completo a la atracción del lugar, hablándonos de tapices de flores y de una "ruta encantada"; de hecho, no hay mejor refuerzo para ello que el paralelismo apuntado entre nuestra región y Egipto, como parte aquí de ese extenso Oriente -en lo geográfico pero también en lo cultural-que tanto atrajo al pensamiento europeo desde mediados del siglo XVIII y hasta bien avanzado el XIX (RODINSON, 1989; MÉNDEZ RODRÍGUEZ, 2008: 15-57). Hay, sin embargo, otro hecho importante: la aparición, al final del fragmento, de un término esencial: paisaje. El texto nos ofrece de este modo una lectura más amplia: Latour construye con la palabra, y ante los lectores de sus Études..., un paisaje en el que el río se convierte en elemento fundamental. Como se ha señalado en diversos estudios sobre la imagen de Andalucia (LACOMBA, 2007: 24), la posición del Guadalquivir en la propia geografía se traslada a su importancia en la formalización del paisaje andaluz como hecho contemporáneo. Bien es cierto que debe aceptarse una excepción a esta regla: me estoy refiriendo al corpus iconográfico vinculado a Granada y a la Alhambra, que seria junto al de las grandes ciudades ribereñas -Córdoba y Sevilla- el otro núcleo en torno al cual se define la 


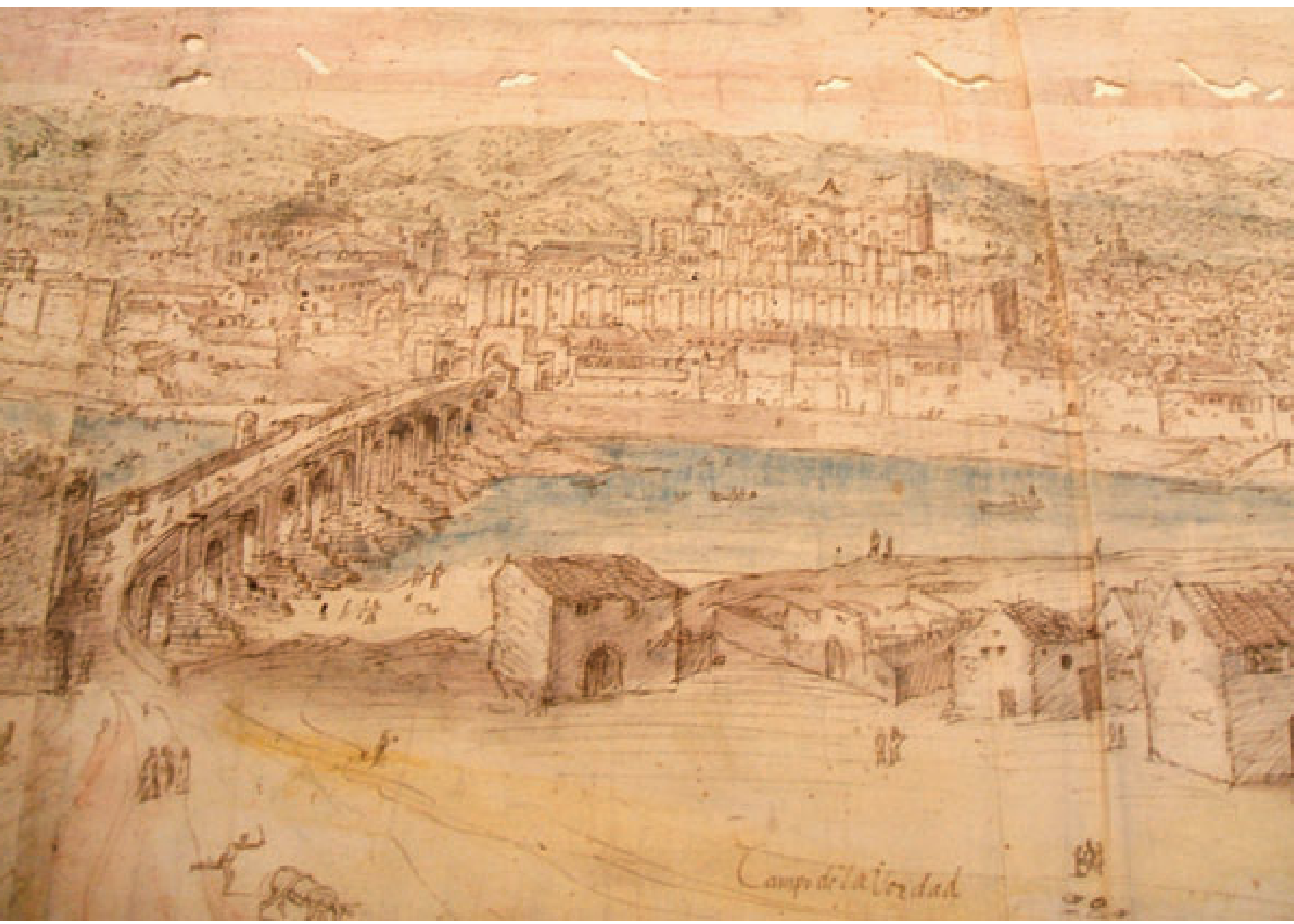

Vista de Córdoba (1567). Anton van Wyngaerde. Detalle. Victoria \& Albert Museum, Londres Foto: Javier Rodríguez Barberán

proyección exterior de Andalucía. Sin embargo, esto ya había venido ocurriendo desde principios de la Edad Moderna: cualquier reflexión en torno a las vistas de las ciudades y los territorios de Andalucia, aun aceptando la diversidad de las representaciones, termina por mostrar con claridad que Granada (GÁMIZ, 2008), Córdoba (COSANO, 1999) y Sevilla (SANTIAGO et ál., 1988; SERRERA et ál., 1989), monopolizan prácticamente la imagen que del sur de la Península lbérica se tiene en el continente.

Esta incursión en el pasado permite invocar el precedente de los siglos XVI y XVII: en las vistas de Sevilla y de Córdoba de este periodo, realizadas por autores como Wyngaerde, Brambilla o Hoefnagel, el Guadalquivir es siempre protagonista al aparecer en primer plano. Córdoba se nos muestra, en esencia, como una ciudad vista desde la margen opuesta del río, con el puente romano y la mezquita-catedral como referencias; Sevilla, por su parte, es la urbe que se vislumbra desde el Aljarafe, con el río ante ella surcado por innumerables barcos y la agitación del puerto de las Indias. Rara vez se modifican estos puntos de vista, y como consecuencia de ello, si vamos más allá de las fronteras peninsulares, para cualquier europeo culto de la era del Humanismo, ambas poblaciones serían, jugando con la frase que Herodoto aplicó a Egipto, "un don del Guadalquivir".

Con estos antecedentes no es extraño que el río desempeñe durante el siglo XIX un papel esencial a la hora de que Andalucia se convierta, ante los ojos de los viajeros continentales y de quienes se enfrentan a sus textos o a sus grabados -por citar las dos herramientas de difusión más extendidas, y a las que se añadirá la fotografía a partir de 1850-, en un territorio propicio para la ensoñación. Siendo extraordinaria la densidad histórica de los acontecimientos vinculados al Guadalquivir, lo más atractivo para la mayoría de los ingleses, franceses y visitantes de otras muchas nacionalidades, parece ser la posibilidad de convertir al río grande en un escenario para las fantasías de la época. Sin embargo, no conviene ceder a la tentación simplificadora de un único río, un río teñido de exotismo y en torno al cual se mueven los personajes del imaginario romántico. Ello significaría renunciar a la pluralidad de registros que cualquier análisis riguroso desvela: la naturaleza del propio siglo así lo demanda, y por ello conviene 


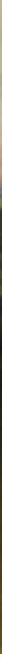

Vista de Sevilla con el Puente de Triana. Manuel Barrón. Palacio Real, Madrid. Fuente: RODRÍGUEZ BARBERÁN et ál., 2007

fuerza de su propia educación y de la costumbre -los carnés de viaje, tan importantes en el mundo del Grand Tour por Europa-, pero también ante el obstáculo insalvable de la ausencia de un medio mecánico de reproducción que está a sólo unos pocos años vista de su irrupción, la fotografía (RODRíGUEZ BARBERÁN et ál., 2007: 116-121). Los dibujos se convierten así en fuente primaria para el libro que elaborará años más tarde, y con ellos el texto se impregnará, como señalan F. Márquez y J. Cascales, de una visión del paisaje muy precisa y estructurada (RODRÍGUEZ BARBERÁN et ál., 2007: 149-165). Es en este contexto donde se insertan las vistas de los alrededores de Sevilla y de sus espacios extramuros que tienen al Guadalquivir como protagonista: de los más de cien dibujos y apuntes de Ford dedicados a la capital andaluza, son al menos quince los que muestran la importancia del río para comprender la propia ciudad y su entorno. Las vistas desde el Aljarafe o desde el meandro, así como las imágenes del cauce cercanas a las murallas, con la Torre del Oro como gran referencia, revelan un carácter poco dado a la ensoñación. Es cierto que el autor se recrea en la belleza del paisaje, pero la dimensión de éste atiende a dos grandes referencias: el desarrollo de la destreza artística y

L la elaboración de una memoria en papel de las sensaciones que trasladaría con el tiempo a su Manual.

No deja de ser curioso que exactamente por esos mismos años un pintor también británico, el escocés David Roberts, realice otra aportación esencial para la imagen de la España del XIX, y con un perfil que complementa a la perfección el de Richard Ford. Entre 1832 y 1833, Roberts recorre la Península (GIMÉNEZ, 2002) elaborando una serie de dibujos y óleos con un objetivo concreto: alcanzar el reconocimiento como artista especializado en el género del paisaje y convertir ese conjunto de obras en la fuente de inspiración de series de grabados. Obsérvese la complementariedad antes señalada: aunque Roberts escribe un interesante conjunto de cartas desde España, su visión se transmite al gran público a través de las estampas que ilustrarán las guías y los libros de viajes de otros autores -curiosamente no el Manual de Ford, que se edita sin ilustraciones- a partir de 1835. Por otro lado, Roberts no es un aficionado, como Ford, sino que es una persona que hace de la pintura su profesión, y que por tanto participa de las corrientes artísticas del momento. En él sí que se manifiesta con claridad la imagen de España como meca del viajero romántico; y además se trata de una imagen en la que, como en el caso de Ford, Andalucia posee un peso extraordinario. Sin tener que recurrir a la ambientación histórica, los dibujos, acuarelas y óleos de David Roberts -y los grabados que surgen a partir de ellos- poseen siempre un carácter evocador de otros tiempos, y se impregnan de una melancolía que los convierte en expresiones precisas de la mentalidad romántica. De un modo diferente a otro artista inglés que viaja por España también a principios de los años treinta, John Frederick Lewis, Roberts es sobre todo 
paisajista, y así lo plasma en dos auténticas obras maestras: los cuadros del Museo Nacional del Prado La Torre del Oro y El castillo de Alcalá. La atmósfera de ambos lienzos nos muestra el río como un ámbito propicio para que los sentimientos y las emociones se pongan de relieve; de hecho, las dos obras están unidas por las últimas luces del día, y el atardecer se convierte así en un elemento central para construir el propio paisaje. Sin embargo, mientras que en la visión de la Torre del Oro la noche no se manifiesta aún, en la imagen de las riberas del Guadaíra con el castillo al fondo, las sombras poseen ya un gran protagonismo. No creo, sin embargo, que resulte casual el hecho de que la vista de Sevilla se convierta en un reproducidisimo grabado (GIMÉNEZ, 2002: 429), mientras que esto no ocurre con la de Alcalá. La presencia de la Torre del Oro concede a la primera el tono "orientalista" del que carece la lejana vista del castillo, y su carácter resulta además mucho más pintoresco gracias a la galería de tipos que aparecen en ella. De hecho, la imagen sevillana se encuentra muy cerca del espíritu de otras obras de Roberts con el Guadalquivir como tema: éste sería el caso de sus vistas de Córdoba, y de modo muy especial la que realiza desde el paseo de la ribera, con las grandes referencias monumentales -puente romano y mezquita-catedral- al fondo, y un grupo de pescadores, vendedores de loza, majos y majas o simples paseantes en primer plano (COSANO, 1999: 88-89).

Lo comentado sobre Roberts da pie también a otra reflexión, que en cierto modo ya manifestaban los dibujos de Ford, aunque se trataran de una obra sin ánimo de difusión: el río podía ser también considerado por sí mismo, sin tener que atender a su inserción en un contexto urbano. Que el pintor escocés se acerque a la pequeña población de Alcalá de Guadaíra, como también lo hizo el francés Eugène Delacroix en su breve paso por España (LACOMBA, 2007: 42), fortalecía el concepto de un paisaje desligado del componente histórico, para poner el foco en las posibilidades plásticas del mismo. Esto, que resultaba extraño a los autores españoles del momento, permitió no obstante abrir caminos que serian explorados en el futuro. Pensemos, por ejemplo, en el pintor gallego Jenaro Pérez Villaamil, uno de los artistas con los que Roberts tuvo relación (GIMÉNEZ, 2002: 283287) y que ya en 1843 había realizado una obra como El Castillo de Alcalá -hoy en el Museo de Buenos Aires (LACOMBA, 2002: 33-34)-, completamente deudora del artista escocés, y donde el río sirve para una reflexión en la que la dimensión plástica y la de la propia escena están bastante equilibradas. Sin embargo, esto no significaba renunciar a que el Guadalquivir continuara siendo soporte de relatos históricos o de ensoñaciones exóticas como nos muestra un cuadro del mismo Pérez Villaamil, fechado en 1848, y en el que la vista del río y la Torre del Oro sirven de excusa para recrear lo que el propio título de la obra hace explícito: Sevilla en tiempo de los moros (LACOMBA, 2007: 26-27). Con ella se demuestra que nos encontramos ante una fase de tanteo, y también lo flexible de las fronteras entre los géneros del paisaje, de la pintura de historia e incluso del orientalismo, en un autor que recoge las influencias europeas y que las consolida en la plástica española.
Ante estas circunstancias, el paisaje fluvial del Guadalquivir empezaria mostrar otros rostros: ya sea explotando la vertiente pintoresca, ya a través de la búsqueda de nuevos efectos para la pintura, el río comienza a ser representado de un modo distinto, que le confiere más protagonismo. En cierto sentido, la plástica comienza a ir de la mano de lo que ya había ido encontrado lugar en las páginas de los libros. Cuando George Borrow describe la Sevilla de 1839 en su famosa obra La Biblia en España contrapone el interior de la ciudad -repleta de calles sucias y angostas, atestadas de mendigos- con el entorno del río. Habla asi del placer de vagar por sus márgenes, de los "largos senderos umbríos" y de un panorama "de inefable hermosura", que ni siquiera podria representar en toda su belleza "el pincel de Claudio mismo" -se refiere al pintor del clasicismo francés Claudio de Lorena-, para concluir con un elemento que el tópico se encargará de repetir hasta el agotamiento:"... respirando las brisas cargadas con el aroma de los naranjales" (BORROW, 1970: 514-515). Las semejanzas entre lo que Borrow comenta y la "ruta encantada" que nos describirá Antoine Latour algunos años después en el texto ya comentado, son más que evidentes. Para ambos el valor del paisaje no radica en la aparición de monumentos singulares o de ruinas que evocan el pasado; la belleza del mismo reside en una naturaleza esplendorosa, que demanda ser descrita por medio de la palabra o trasladada al lienzo. Comienza así la construcción de una nueva imagen del territorio en la que el Guadalquivir desempeñará un papel muy importante, y que arranca, como ya hemos mencionado, de la deriva costumbrista del Romanticismo para alcanzar un primer hito durante la segunda mitad del siglo con la consolidación del paisaje realista (LACOMBA, 2007: 49-73).

Basta con revisar los repertorios iconográficos realizados sobre las ciudades ribereñas -de especial relevancia es el caso de Sevilla (CALVO, F. et ál., 1991), con el interesante añadido de lo que más adelante se conocerá como la Escuela (paisajista) de Alcalá de Guadaíra (LACOMBA, 2002)- para advertir este cambio, que es en realidad el reflejo de las transformaciones económicas, sociales,

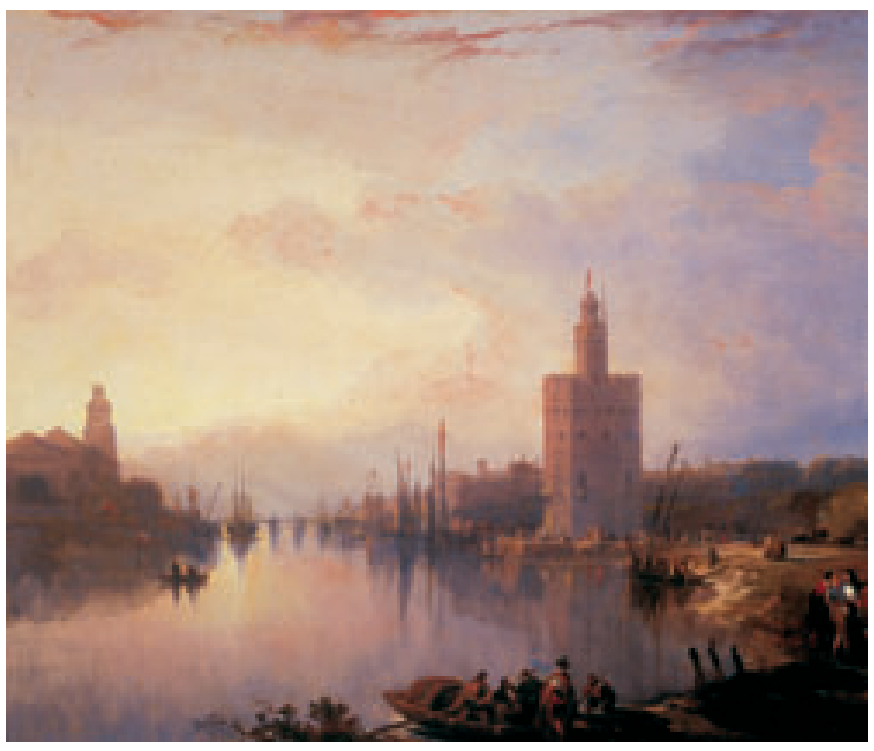

La Torre del Oro. David Roberts. Museo Nacional del Prado, Madrid. Fuente: RODRIGGUZ BARBERÁN et ál., 2007 
culturales y, por ende, urbanas, de la España isabelina. Aunque el sustrato del pintoresquismo no se ha esfumado, ello parece obedecer tanto a la propia formación de los artistas como a las características de la producción pictórica, planteada muy a menudo para un mercado -de viajeros, pero también de clases acomodadas del país- que demanda estas obras por su carácter esencialmente decorativo (MÉNDEZ RODRÍGUEZ, 2008: 73-77). Autores como Andrés Cortés y su extenso taller, o Manuel Barrón (LACOMBA, 2007: 53-58) responderian, durante las décadas de los cincuenta y los sesenta sobre todo, a estos principios. No obstante, un análisis de este periodo pecaría de superficialidad si no se pusieran de relieve otras cuestiones que se hacen presentes en ese momento. Me refiero, sobre todo, a la influencia de la fotografia, que comienza a popularizarse como souvenir para los turistas y como ilustración de publicaciones a partir de 1850. Frente a la destreza manual, el nuevo medio propone una acción mecánica, ligada al desarrollo tecnológico. Precisamente por ello no colisiona con la pintura, sino que se pone, en sentido figurado, al servicio de ésta: el cuaderno de apuntes puede ser sustituido por la cámara, o por el resultado del trabajo del fotógrafo -las colecciones de imágenes en forma de postales-, que se incorpora a las herramientas con las que trabaja el pintor. Además, por su carácter moderno, la fotografía tiende a ofrecer nuevas perspectivas, y a seleccionar otros objetos ante al objetivo, ya que quiere convertirse en un testigo de su tiempo. Que Manuel Barrón, un artista formado en la tradición, ejecute una vista del río en la que el protagonista es un "artefacto sin pasado" (RODRÍGUEZ BARBERÁN, 2008: 47) como el Puente de Isabel II -conocido popularmente como Puente de Triana- sirve para testimoniar a la perfección estos cambios.

Resulta singular la coincidencia de que el año en que se ejecuta esta obra -1862- sea el del mencionado periplo de Davillier y Doré por el Guadalquivir. A los viajeros franceses el río no les cau- sa la impresión que produjo en algunos de sus antecesores: apenas hay un breve apunte histórico y alguna critica a su estrecho cauce (DAVILLIER, 1988: 373-379). No obstante, hay en él algo que les interesa mucho más: Ios toros que aparecen en las dehesas sirven de excusa para trasladarnos, a través de un picador con el que comparten el viaje, al peculiar mundo de las corridas. El espacio del río es, para ellos, el marco sobre el cual superponer los trajes típicos, el ritual de la fiesta y la galería de figuras singulares. El Guadalquivir, por tanto, vuelve a multiplicarse: Io pintoresco convive con el presente retratado con la precisión de la cámara fotográfica, y al mismo tiempo se van sentando las bases para que pueda convertirse en el paisaje realista de los pintores que hallarán en él una versión española de la École de Barbizon. Quizás por ello no resulte contradictorio que alguien aficionado a la pintura y acostumbrado a crear sugerentes imágenes con la palabra, el poeta Gustavo Adolfo Bécquer, vea el río como contrapunto de una ciudad que ya no reconoce. En noviembre de 1862 publica en el periódico El Contemporáneo la leyenda La Venta de los Gatos (BÉCQUER, 2004: 327-335). Bécquer expresa en ella su desencanto ante las transformaciones del paisaje urbano y humano de Sevilla, comparándola con sus recuerdos, indudablemente idealizados. Sus paseos por calles y plazas le llenan de insatisfacción, y sólo el Guadalquivir le ofrece consuelo. Alli, precisamente desde el puente de Isabel II, disfruta de un "magnífico panorama", repleto de "mil detalles ... pintorescos"; admira las márgenes repletas de "jardines, palacios y blancos caseríos", y su mirada se pierde en el cauce, con "los innumerables buques ... que desplegaban al aire los ligeros gallardetes de mil colores". La estampa literaria tiene el aire de las postales coloreadas que empezarán a comercializarse en el último tercio deI XIX, y parece convertirse con ello en tránsito simbólico hacia una idealización del río, pero también de Andalucía, que el siglo XX verá nacer. Pero ése es otro paisaje.

\section{En la web}

\section{GUADALOUIVIR, RÍO DE HISTORIA} www.guadalquivirriodehistoria.es

Organización dedicada a divulgar el patrimonio cultural en torno al río Guadalquivir. El sitio web muestra la ruta "Derroteros del Guadalquivir", sobre el Guadalquivir de los siglos XVI al XVIII. Jornadas y exposiciones son algunos de los recursos disponibles.

\section{ASOCIACIÓN COMARCAL GRAN} VEGA DE SEVILLA

wWw.gvs.es

Este sitio web presenta tanto el Plan Estratégico Gran Vega (2007-2013) como información sobre los municipios que conforman la comarca de la Gran Vega.

\section{CONFEDERACIÓN HIDROGRÁFICA DEL GUADALQUIVIR \\ www.chguadalquivir.es}

En el portal web de este organismo podremos encontrar información exhaustiva sobre la demarcación hidrográfica del río Guadalquivir, datos socioeconómicos, información medioambiental y cartográfica, entre otros recursos de interés.

\section{SCARPIA}

www.scarpia.es

Espacio para la creación contemporánea en el municipio cordobés de El Carpio. En este sitio web se puede encontrar un recorrido por las intervenciones y conferencias realizadas desde el 2002 junto a referencias de webs de los distintos artistas participantes e invitados. Presentación de las últimas jornadas realizadas: Jornadas de Intervención Artística en el Espacio Natural y Urbano.

\section{JARDÍN BOTÁNICO DE CÓRDOBA}

www.jardinbotanicodecordoba.com

El molino de Martos forma parte del patrimonio etnológico y etnobotánico del Jardín botánico de Córdoba. Su sitio web ofrece información histórica, glosario e imágenes del molino así como su relación con el entorno.

\section{CÓRDOBA EN 3D}

martoos.blogspot.com

Animación 3D del molino de Martos así como imágenes históricas es lo que podemos encontrar en este blog.

\section{AYUNTAMIENTO DE PEÑAFLOR (CÓRDOBA)}

www.penaflor.es

La web del Ayuntamiento de Peñaflor ofrece información sobre la historia del municipio, con datos del enclave romano de Celti. 